\title{
Formação humana e educação no contexto de mundialização do conhecimento: sentidos
}

\author{
Human formation and education in the context of knowledge globalization: meanings \\ Formación humana y educación en el contexto de la mundialización del conocimiento: sentidos \\ Vitória Helena CUNHa ESPÓSITO ${ }^{1}$; MARTHa ABraÃo SAAd LUCCHESI ${ }^{2}$; \\ Gilberto TADEU REIS Da SILVA ${ }^{3}$; MARISTEla Ross de CASTro Gasonato ${ }^{4}$ \\ Pontifícia Universidade Católica de São Paulo, PUC-SP, São Paulo-SP, Brasil \\ Universidade de São Paulo, USP, São Paulo-SP, Brasil

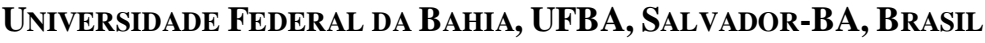

\section{RESUMO}

Este trabalho resgata o sentido original do termo formação e interroga, na educação, o papel do conhecimento no atual contexto de mundialização. Corrobora os estudos que têm, contemporaneamente, denunciado o deslocamento do sentido local, comunal do conhecimento para um contexto de mundialização, comumente chamado por "cidade educativa". Estas investigações de natureza hermenêutica fenomenológica revelam, a partir das descrições dos sujeitos investigados que, ao desconsiderar as idiossincrasias, as experiências que dizem da diversidade cultural, tanto regional como multicultural de seus atores, estes passam a privilegiar saberes tradicionalmente validados, terminando por expropriar do conhecimento humano seus aspectos fundantes geradores de compreensões. Situados num contexto de mundo em transformação, os homens se educam (e-ducere) e são educados (e-ducare), e, neste movimento sempre inacabado, produzem cultura... formam-se.

Palavras-chave: Pesquisa em Educação. Formação Humana. Mundialização do Conhecimento.

\begin{abstract}
This study brings back the original sense of the word formation, and questions the role of knowledge in education in the present context of globalization. It corroborates the contemporaneous studies that have exposed the displacement of the local, communal sense of knowledge to a context of globalization, also known by "educative city". These investigations of hermeneutical and phenomenological nature reveal, based on descriptions of the investigated subjects that, by disregarding the idiosyncrasies, the experience that tell of their cultural diversity, both regional and multicultural, they favour the traditionally validated knowledge, and end up by expropriating from human knowledge its basic aspects that generate comprehension. Situated in a context of world in transformation, men educate themselves (e-ducere) and are also educated (e-ducare), and, in this eternally unfinished movement, they make culture... forming themselves.
\end{abstract}

Keywords: Research in Education. Human Formation. Knowledge Globalization.

\section{RESUMEN}

Este trabajo rescata el sentido original del término formación e interroga en la educación el papel del conocimiento en el actual contexto de mundialización. Corrobora los estudios que, al mismo tiempo, denuncian el desplazamiento del sentido local, comunal del conocimiento hacia un contexto de mundialización, comúnmente llamado "ciudad educativa". Estas investigaciones de naturaleza hermenéutica fenomenológica revelan, a partir de las descripciones de los sujetos investigados que, al desconsiderar las idiosincrasias, las experiencias que dicen de la diversidad cultural, tanto regional como multicultural de sus actores, estos pasan a privilegiar saberes tradicionalmente validados, terminando por expropiar del conocimiento humano sus aspectos fundantes generadores de entendimientos. En un contexto de mundo en transformación, los hombres se educan (e-ducere) y son educados (e-ducare), y, en este movimiento siempre inacabado, producen cultura... se forman.

Palabras clave: Investigación en Educación. Formación Humana. Mundialización del Conocimiento.

\footnotetext{
${ }^{1}$ Professora Titular da Faculdade de Educação da PUC-SP. E-mail: vitoriaesposito@ @otmail.com

${ }^{2}$ Pesquisadora Sênior do Núcleo de Políticas Públicas (NUPPs) da USP. E-mail:

mgrlucchesi@uol.com.br

${ }^{3}$ Professor Titular da UFBA. E-mail: gilberto.tadeu@ufba.br

${ }^{4}$ Membro do Grupo de Pesquisa Educação e Produção de Conhecimento da PUC-SP. E-mail: maristelagasonato@gmail.com
} 


\section{INTRODUÇÃO}

O contexto mundial nos coloca face a face com situações inesperadas, de diferentes naturezas e nos faz vivenciar pela falta, a necessidade de algo que parece ter se perdido no tempo e no espaço, algo da condição humana originária, que se mostra irredutível a outras causalidades ou explicações que estejam além do próprio fenômeno. Esta situação produz marcas que perpassam nossos corpos determinando modos de ver e apreender as coisas e na forma como ao projetar caminhos focalizamos alguns, obscurecendo outros, fazendo com que se percam as diferenças que nascem do "entre si”, berço da profundidade que a velocidade esgota e suprime reduzindo o ser humano a ter da realidade um espectro, pois a linearidade estática que prevalece estabelece modos de apreender as coisas que aí estão na regularidade, determinando efeitos, predizendo, controlando. Essa apreensão leva à hegemonia de um tempo mecanicista, seja pelas marcas que se refletem no currículo escolar, seja pela predominância de uma ordenação disciplinar da episteme $e^{5}$ que se utiliza de uma metodologia pouco preocupada com outras organizações do pensar. Conforma-se assim, desde cedo, o modo de nos dirigirmos às coisas sem nenhum ou quase nenhum questionamento. Basta dizer que fomos alfabetizados sob a égide de métodos - fonéticos, silábicos ou globais - sem saber que estruturas de pensamento foram assim se formando em detrimento de quê.

Mais ainda, o termo "conhecimento" é utilizado em nosso cotidiano sem que nos preocupemos em investigar os diferentes sentidos que na História foram sendo forjados para esta palavra. Dela nos servimos como se fosse reconhecida por todos, usada sem que qualquer sombra de dúvida pudesse vir a pairar sobre sua constituição. Entretanto, sua origem grega, e mesmo latina (co+gnoscere), fala de nascimento, refere-se a um ato intencional, num sentido genético, significando nascimento tal como na palavra francesa conaissance. Tomado na sua origem sânscrita (jñana), conhecimento significa "captação conjunta" e "com-preensão" (ESPÓSITO, 2006).

Conhecimento, nessa perspectiva, representa o fundamento da vida mental e consciente. É seu significado central, para além de outros sentidos, que adquiriu ao longo da história, quando oscila entre o sentido forte do termo "conhecimento" como compreensão, participação ou realização e o de mera reprodução de conteúdos, conformadora de condutas. Contém em si, pois, no primeiro caso - como participação o germe da construção de conhecimentos genuínos, prático-poiéticos, criadores.

Como participação, torna-se possível ver o caráter de construção que desta palavra emana, quando o ser enraizado na sua existência pela mediação do corpo vê-se situado no espaço e no tempo, ser histórico, habitando a carne do mundo. Esse modo de compreender o conhecimento nos leva a retomar Bloom (1977), que observa que o conhecimento abarca comportamentos e situações objetivas, passíveis de verificação e explicações, enquanto a compreensão, processo mais sutil, enfatiza a atribuição de significados, de forma que, ao expressá-los, o sujeito o faz de maneira análoga àquela que lhe pareça com mais sentido. Nesta empreitada, esse novo sentido pode ir além do que lhe foi oferecido na própria comunicação, gerando transposições.

Consideramos que esta configuração que se gesta na experiência comunicativa surge de tensões, resultando de situações vividas significativamente pelo sujeito cujas

\footnotetext{
${ }^{5}$ Por episteme Michel Foucault compreende um a priori histórico que num dado período delimita, na totalidade da experiência, um campo do saber, definindo o modo de ser dos objetos que aparecem nele, apresentando modelos teóricos à percepção cotidiana do homem e definindo as condições em que se pode sustentar um discurso sobre as coisas que são reconhecidas como verdadeiras (MERQUIOR, 1985, p. 50).
} 
explicações dadas são insuficientes para dizer de como o homem apreende o mundo e as coisas que nele estão.

\section{PerCuRSOS METOdOLÓGICOS DE PESQUiSA: EM BUSCA DE SENTIDOS}

Nas perspectivas trabalhadas trazemos aqui um relato de estudos efetuados no âmbito da Cátedra Joel Martins (ESPÓSITO et al., 2014), que se desenvolvem como um percurso metodológico e que focam a experiência dos sujeitos que vivenciam a indissociável interface saúde-educação numa perspectiva inter/multi e transdisciplinar. Com estes estudos e de forma coerente às suas proposições a Cátedra Joel Martins ${ }^{6}$ enfatiza que a consciência pré-reflexiva e pré-objetiva presente nos discursos fenomenológicos mostra-se de forma especial para a compreensão dos modos pelos quais os sujeitos envolvidos na investigação vivenciam seu fazer, formulam sentidos, produzem conhecimentos. Nesta intencionalidade a Cátedra, ao produzir e divulgar estudos e trabalhos tem contribuído para a construção de estruturas de pensamento, de forma a influenciar, orientar e subsidiar atividades voltadas ao desenvolvimento humano e à produção de ações educativas, imprescindíveis para o enfrentamento dos desafios que o mundo contemporâneo nos impõe, e assim dar suporte à concretização das múltiplas relações, especialmente entre educação, saúde, cultura e sociedade (ESPÓSITO; SILVA, 2012). Como suporte metodológico, a fenomenologia hermenêutica tem propiciado a leitura compreensivo-interpretativa das pesquisas apresentadas.

Salientamos a necessidade de se investir em uma postura crítica nas investigações sistemáticas; no discernimento de que é possível fazer ciência a partir da experiência vivida e da intervenção na realidade concreta. Concluímos ainda que a construção de conhecimento, de ações educativas humanizadoras e de cuidados, constitui-se num fazer transformador em constante (re)construção.

E o que nos trazem ainda estas investigações?

Com relação à formação profissional, Silva (2003), na sua tese doutoral e ao estudar a formação profissional constata que os alunos, ao dizerem da ação educativa por eles vivenciada no curso de Graduação de uma instituição de ensino superior da Grande São Paulo, inicialmente enfatizam uma perspectiva de formação que apresenta a crença de que todos os questionamentos e dúvidas deverão ser sanados antes de sua graduação, quando então estariam formados. Expressam assim a sua percepção de formação como algo que se limita a um período de quatro anos.

Entretanto, emerge também desta pesquisa a referência à temática coexistência, que traz como sentido mais amplo e próprio da condição humana o ser e estar no

\footnotetext{
6 A Cátedra Joel Martins foi instituída pela Deliberação PUC-SP de no 35/2008 de 19/12/2008, publicada em 05/2009, tendo como sede a Faculdade de Educação da PUC-SP. Tem encontrado seu locus principal de estudo, pesquisa e diálogo na Sociedade de Pesquisa Qualitativa em Motricidade Humana (ESPÓSITO; SILVA, 2012). Por sua vez, o Prof. Dr. Luiz Gonçalves Junior, atual Coordenador da Cátedra Joel Martins, nas suas referências à mesma sempre nos lembra de que esta possui membros de distintas Instituições (PUC-SP; UFSCar; UFBA; UNESP; UNIFESP; entre outras) trabalhando de modo cooperativo, visando, conforme objetivos específicos três e quatro delineados na proposição da Cátedra: 3. Integrar esforço conjunto entre comunidades e instituições dispostas a estabelecer parcerias, incentivando a construção de espaços educativos voltados à Educação para todos, especialmente no que tange à alfabetização linguística e à capacitação essencial para a vida; 4. Programar contatos para o estabelecimento de parcerias regionais, nacionais e internacionais. Mais ainda, nos diz da tarefa desta Cátedra quanto à produção de conhecimento e ao desenvolvimento de ações educativas, sempre em prol da tolerância, da solidariedade e do acolhimento à diversidade, em uma cultura de paz (ESPÓSITO; SILVA, 2012).
} 
mundo, almejando compreender esse modo de ser/estar com o outro. Observamos, de forma significativa, que ao se manifestar na pesquisa o pesquisador acredita que sua vida acadêmica o aproxima da atuação profissional e docente, como ser no mundo. No instante em que isso ocorre, temos como possibilidade apreender o conhecimento libertador, autêntico, e não apenas a mera reprodução de conhecimento. O docente, ao acolher o aluno, estará possivelmente expressando uma postura ativa e reconhecida como própria, democrática. Considera que o aluno deve ser estimulado em sua capacidade imaginativa, através do estudo crítico de modelos de organização do pensamento e de percepção da realidade. Desta ótica, é preciso compreender a prática docente como trabalho humano, construída por sujeitos inseridos em um espaço histórico e socialmente localizado, uma dimensão fundamental na vida humana, capaz de transformar o homem em seu mundo/vida, nos seus aspectos objetivos/subjetivos/intersubjetivos. Mais ainda, considera que: ensinar e aprender imbricam-se na existência. Assim sendo, o docente na vivência da sua ação compreende-se como um ser que é formador/preceptor/educador, um ser ôntico/ontológico, ser que é corpo e habita a corporeidade do mundo, e que "sendo", na concretude da ação educativa, dispõe-se a intervir, transformando.

Ainda em Silva (2003) vemos que na convivência cotidiana com a presença do professor é que o aluno constrói uma aproximação - uma ponte - entre mundos. É com a realidade do mundo exterior, presente em toda sua variedade e diversidade existente na palavra e ação do professor e no vivido, que ambos reconhecem as dificuldades e evidenciam-se os passos da autonomia, da liberdade e os sucessos possíveis. Ao orientar-se pela convivência que se estabelece em sala de aula ou no campo da prática e na preceptoria, o aluno, enquanto presença, empreende a construção do conhecimento, sua e do outro como ser-no-mundo.

Mais ainda, nas investigações de natureza interdisciplinar e multiprofissional relatadas (SILVA et al., 2008), o autor observa que os profissionais de saúde são frequentemente formados com visões distorcidas das reais necessidades do cotidiano assistencial, tendo por premissa a visão fragmentada dos processos de construção das identidades profissionais que privilegiam as corporações, assim acarretando a quase inexistência de reciprocidade, interação, complementaridade ou cooperação mútua entre setores e, sobretudo, entre profissionais. Ao nos conscientizarmos da existência de nichos, espaços vazios, entre as diferentes regiões ontológicas de conhecimento especializado, um entre-si, estes se mostram, ao não serem percebidos, por um lado como uma das possíveis causas do distanciamento disciplinar que percebemos existir na prática inter-multi-profissional, sobretudo quando vislumbramos os poderes paralelos que são criados culturalmente; por outro lado - se percebidos - abrem espaço para que se dê o novo, o inusitado.

Cabe ressaltar que a formação na área de saúde em sua maior parte, se desenvolve com um quantitativo de formação teórica e prática, todavia distanciada da humanização nas relações entre os educandos e educadores. Deve-se também destacar que estes percursos formativos se dão de maneira uniprofissional, sendo que, após tal ação o exercício profissional se dá em equipe de saúde, ou seja, em equipe multiprofissional.

Dessa maneira, a multiprofissionalidade pode ser um exercício, uma estratégia visando colocar o ser humano na existência e diminuir os distanciamentos apontados anteriormente. E mais, diante do estudo trazido por Nunes et al. (1998) é importante perceber que a multiprofissionalidade é uma tendência global e que sua utilidade na atuação em saúde tem destaque no trabalho que desenvolva ações de promoção, prevenção e reabilitação em saúde, o que motiva as ações em equipes colaborativas. Em face dessa explicitação, é importante refletir sobre a necessidade de currículos 
descompartimentalizados, diminuindo a resistência à colaboração interprofissional. Na diversidade que marca as conceituações e práticas interdisciplinares, é possível identificar pontos comuns: o sentido de relação, a valorização da história dos diferentes sujeitos/disciplinas envolvidas, o movimento de questionamento e dúvida, a busca por caminhos novos na superação de problemas colocados no cotidiano, a ênfase no trabalho coletivo e na parceria e o respeito pelas diferenças (UNIFESP, 2006).

$\mathrm{O}$ projeto de pesquisa, cujas investigações citamos anteriormente, se desenvolveu até 2015, junto a um Programa de Mestrado Profissional da Universidade Federal de São Paulo. Dele resultaram quatro dissertações de mestrado que abordaram perspectivas diferenciadas da formação profissional e multiprofissional em saúde, tanto em ambiente de residência multiprofissional quanto da educação em saúde em instituição federal de ensino superior e na formação de nutricionistas em ambulatório de pacientes submetidos a cuidados especializados, com a imprescindível participação da equipe multiprofissional.

Nessa trajetória, o autor retoma a fala de Joel Martins (1992) ao dizer que, numa perspectiva hermenêutica e fenomenológica, o ensinar e o aprender num currículo como poíesis consiste na possibilidade que tem o ser humano de tomar consciência da necessidade de ver-se inserido no mundo humano, um ser com o outro, e então reorganizar um projeto de vida.

Ainda no âmbito dos estudos da Cátedra Joel Martins, focando a experiência dos sujeitos que vivenciam a indissociável interface saúde-educação numa perspectiva inter/multi/transdisciplinar, trazemos aqui os trabalhos de Gasonato (2008), que retomam os resultados capturados em pesquisa desenvolvida na modalidade qualitativa com fundamentação fenomenológica existencial e hermenêutica durante sua graduação em Pedagogia, avançando com os estudos desenvolvidos contemporaneamente pelo Grupo de Pesquisa Educação e Produção de Conhecimento (CNPq-PUC-SP). Destes estudos, trazemos a preocupação em produzir uma reflexão aproximando ensino e pesquisa, pois acreditamos que pesquisar e educar se identificam em um permanente e dinâmico movimento.

Corroborando com outro trabalho (ESPÓSITO; GASONATO, 2016), em suas pesquisas a autora nos traz de forma convergente que assim como a existência num mundo de cultura é inerente ao ser humano, essa existência traz aspectos culturais e sociais ao ser em si; ou seja, categorias já dadas, teorias já validadas, estabelecem um óculo perceptual e social que pro-jeta ideologicamente compreensões, interpretações e explicações. É como se o mundo simbolicamente já contivesse tudo aquilo de que precisamos, levando-nos a vê-lo através do olhar do outro. Tradicionalmente, a cultura de dominação privilegia este modo de pensar o mundo, favorecendo sim, a liberdade para, mas não a liberdade de. Liberdade de se saber ser histórico, de se saber capaz de interferir conscientemente em seu próprio tempo, um ser que não apenas está no mundo, mas com o mundo. Estar com o mundo resulta de sua abertura à realidade, que o faz ser o ente de relações que é (ESPÓSITO et al., 1999). Concluindo, constatamos que ensinar, aprender, pesquisar - palavras que, vistas em "situações educativas", nos dizem do homem como um ser fadado a conhecer - é dizer da liberdade que se faz cotidianamente na concretude da existência humana. Conceber este homem na sua historicidade, como construtor de conhecimento é enredar-se no dilema frente às suas facticidades, saber-se também um ser de decisões.

\section{RETOMANDO O FLUXO DO PENSAR}


Vitória H. C. Espósito; Martha A. S. Lucchesi; Gilberto T. R. da Silva; Maristela R. de C. Gasonato

$\mathrm{Na}$ continuidade de nossos trabalhos e em outra perspectiva, vemos que o conhecimento também pode ser entendido de vários modos na sociedade contemporânea. Se por um lado ele é valor econômico, que se produz e se distribui na sociedade em rede, que é a sociedade do conhecimento, por outro lado, continua sendo uma construção interior de cada ser, individual, subjetiva e intersubjetiva, pois também social, que se produz na articulação homem/mundo, seja no ambiente local e familiar, seja no contexto global, planetário. Touriñán López (2004) aborda a possibilidade da articulação entre o local e o global, à qual denomina de "glocal". Este seria, no seu entender, o caminho que possibilitaria a inserção do homem na sociedade global, sem perda da identidade particular, e da percepção das necessidades específicas de cada nação, região, cidade ou grupo social. Nesse segundo sentido, muitas vezes tem-se preferido empregar o termo "saberes" para designar aquele conhecimento que o sujeito possui, que retém e cultiva dentro de si e no seu fazer.

Mas os "saberes" não são sinônimos de "conhecimento", especialmente se tomamos esta palavra a partir de diferentes concepções filosóficas (MATTELART, 2005), as quais podem nos revelar as diferenças quanto à finalidade social perseguida pela remodelação dos fundamentos de uma sociedade. Mas o que queremos pôr em destaque é que o conhecimento se constrói na articulação entre o "dentro" (na interioridade do Ser) e o "fora" (no mundo) numa relação dialética sempre inacabada (onde o ser que se modela é modelado culturalmente). Dizendo de outra forma, o conhecimento deve ser entendido como resultado de um processo interno, pelo qual o ser humano se apropria da informação, que circula no mundo, e do saber, que vive e elabora internamente, inclusive no seu inconsciente. Um processo que é subjetivo/intersubjetivo/intercorporal, social e cultural.

Numa concepção fenomenológica hermenêutica, tal como a compreendemos, o ato do conhecimento se dá quando a consciência se dirige para algo ou alguém gerando uma relação noemática. Disto decorre que a intenção de significar é um pré-requisito para que possa ocorrer uma experiência perceptual (MERLEAU-PONTY, 1999), quando há um encontro entre a consciência que se dirige para o mundo e um mundo exterior, que se doa à consciência. No caso em discussão, para aquele que aprende (o aluno), àquele que ensina (o professor) caberá propiciar que ocorra a correlação (noesisnoema-noesis), quando resultará, fruto desta dialética de oposição sempre inacabada homem/mundo/homem, um ato de compreensão, condição indispensável para que se dê a produção do conhecimento (MARTINS, 1992). Observamos aqui que o percebido em decorrência deste ato intencional (noesis) é a experiência vivida real (Erlebniz), que é diferente da simples experiência informativa (Erfharung).

Consideramos importante destacar que foi no limiar deste último século, através de Paul Ricoeur (1996), que agregou a fenomenologia hermenêutica aos estudos da semiótica e da linguística, que nos vimos colocados em face de uma forma não excludente e dicotômica de abordar o conhecimento humano; sem segmentá-lo, seja percebendo-o como fenômeno, numa abordagem compreensiva, seja na sua dimensão explicativa e factual. O elemento superador desta suposta segmentação está na possibilidade de apreender-se a dialética fina que ocorre entre a inteligibilidade que se organiza silenciosamente como um discurso do silêncio, na interioridade do Ser - e que, ao estruturar-se na inteligibilidade humana, solicita ser expressa em linguagem. Esta dialética fina, gênese da linguagem, ao ser posta no mundo, solicita comunicar-se. 
Mostra-se, neste modo de organização, um arco hermenêutico que se dá no movimento entre a parte e o todo, a subjetividade/intersubjetividade, o homem que é corpo na corporeidade do mundo, numa dialética de oposições sempre inacabada ${ }^{7}$.

$O$ contexto de mundialização que vem sendo denominado de "sociedade do conhecimento" (knowledge society), ou "sociedades de saberes" 8 traz novas dicotomias e complexidades para o ser humano, ressaltando-se a importância da postura filosóficohermenêutica dos sujeitos envolvidos no processo diante do conhecimento, da cultura e da sociedade, como possibilidade para superar a contradição entre saberes e seu ser/fazer. Isso pode ser concretizado a partir da pesquisa, a constante busca e interesse em decifrar os enigmas postos pelas questões que passam na sociedade, para o devir. Isso, no dizer de Maffesoli (2010, p. 32), permitiria "fazer com que se manifestassem", "no devir espiralesco do mundo", as "características da episteme pós-moderna". Para Bauman (1999, p. 250), "[...] é inteiramente diferente viver com a consciência pósmoderna de que não há nenhuma saída certa para a incerteza; de que a fuga à contingência é tão contingente quanto a condição da qual se busca fugir".

A transformação epistemológica pela qual vêm passando a produção e a difusão do conhecimento não mais permite a segmentação dos espaços de pesquisa de ensino e de extensão em áreas compartimentadas (LUCCHESI; MALANGA, 2008, p. 1546). E como isto se dá na ação educativa dirigida ao formar? Para além da interpretação compreensiva, a ação educativa solicita explicações. Estas gestam-se a partir de uma dialética fina entre o conhecimento considerado culturalmente válido e as compreensões que surgem da inteligibilidade que se articula como discurso na interioridade do ser e, assim sendo, buscam sentidos, solicitam linguagem. Solicitam ainda, no processo, extrapolações, movimentos que geram novos conhecimentos, levando a possíveis intervenções na concretude do mundo, o que implica, mais do que transladar e interpretar, "transfazer". O processo de produção do conhecimento requer que o sujeito projete tendências para outros lugares, tempos e espaços; investigue, busque novos

\footnotetext{
${ }^{7}$ Destacamos aqui, no âmbito da Sociedade de Pesquisa Qualitativa em Motricidade Humana (SPQMH), a proposta do VII Colóquio de Pesquisa Qualitativa em Motricidade Humana (UFSCAR, 2017). Segundo o entrevistado, Prof. Dr. Luiz Gonçalves Junior, há uma mudança no enfoque comumente trabalhado da Educação Física para a Motricidade Humana, nesta última “[...] partimos do corpo-objeto para corpopróprio, o corpo encarnado" (UFSCAR, 2017, p. 1). Esse novo paradigma compreende o ser como intencionalidade, que se dirige para o mundo, às coisas e aos demais seres humanos com os quais compartilha o mundo. Mais ainda, "Na área de Motricidade Humana é ímpar a importância da pesquisa qualitativa, já que essa metodologia favorece estudos que consideram o ser humano em sua integralidade" (UFSCAR, 2017, p. 1). Observa ainda o entrevistado, a sinergia entre a Ecomotricidade e o Bem Viver. A Ecomotricidade entendida como " [...] as práticas desenvolvidas com intencionalidade relacionada a processos educativos de reconhecimento das relações ser humano-ambiente, que primam pelo diálogo entre Educação Ambiental, Motricidade Humana e Pedagogia dialógica" (UFSCAR, 2017, p. 1); e Bem Viver - descrito como "[...] o princípio dos povos indígenas latino-americanos que propõe alternativa à ideia moderna do progresso" (UFSCAR, 2017, p. 1). Amplia-se desta forma a "[...] discussão em torno dos estudos de Motricidade Humana, em diálogo crítico e igualitário com outras epistemologias e outros projetos coletivos estéticos que primam pelo convívio, pela coexistência e pela corresponsabilidade" (UFSCAR, 2017, p. 1).

8 “ “...] diferentemente da noção de sociedade da informação guiada apenas pela tecnologia, as "sociedades de conhecimento" são "minddriven" guiadas pelo espírito. Por outro lado, a recusa em se recorrer à noção singular de "sociedade global" e de se adotar a noção plural de "sociedades" ratifica o fato de que os modos de apropriação das tecnologias são resultado da diversidade das configurações de atores inscritos nos contextos institucionais, culturais, industriais e políticos. Em síntese, é reconhecida a especificidade dos "regimes epistêmicos" [...] A noção de "conhecimento" vem do termo inglês "knowledge". Ora, a etimologia da palavra inglesa "knowledge" está estreitamente ligada ao seu verbo auxiliar "can". Ambos remetem à utilidade e ao poder. Nas línguas latinas, ao contrário, existe um termo alternativo: "saber", cuja etimologia está ligada à raiz indo-européia "sap", "saber" e "ter o sabor de", de onde se originam palavras como "sabedoria", "sapiência". O saber remete à teoria” (MATTELART, 2005, p. 14).
} 
sentidos, possibilidades para além dos conhecimentos já postos, das explicações dadas, e intervenha em direção a outros fazeres.

A ciência clássica, que se formalizou a partir do século XVIII, privilegiou o conhecimento factual e objetivo, disseminou e/ou socializou a informação, ou seja, o conhecimento que está (metaforicamente) "fora" do sujeito cognoscente. Podemos dizer que nesse conhecimento (factual) focava-se a pesquisa e o ensino. Dissemos "focavase", mas o verbo poderia estar no presente no que diz respeito à maior parte da produção voltada para a educação, seja ela básica ou superior. O ensino que se propõe a criar conhecimento na perspectiva que considera o movimento e a experiência perceptual (e não a percepção tal como posta pela psicologia clássica) é a exceção e não a regra. De modo geral, a escola pretende transferir culturalmente certos conhecimentos e não outros e, apesar do discurso construtivista das últimas décadas, ignora a dimensão idiossincrática e cultural do ser que aprende e se faz presente àqueles que se propõem a ensinar. O que mudou foi a forma de transferir o conhecimento e a maneira de avaliá-lo, mas pouco ou nada se fez para uma transformação epistemológica que permita ao aluno produzir conhecimento a partir das suas compreensões e das informações do professor e, dessa maneira, realmente aprender.

Para além, vemos que o problema se situa em grande parte na ambiguidade e ambivalência da concepção que rege a produção de conhecimento e portanto, na formação universitária do professor, uma vez que este nem mesmo no curso superior aprendeu que o conhecimento se produz, e muito menos como fazê-lo. Os métodos de ensino se sucedem e se substituem, mas não têm privilegiado buscar a essência da questão, de forma a subsidiar um ensinar que supere a separação entre o ser e o mundo, ou seja, que considere o pré-reflexivo do sujeito cognoscente (e, portanto, aprendente) e o mundo cognoscível; mais ainda, que considere nesta relação como o professor compreende e interpreta seu professorar. A dimensão existencial na produção do conhecimento continua a ser dita, mas não vivida, e seu fazer uma incógnita.

Para que se aprenda não bastam professores, é preciso que alguém seja ensinante. O termo ensinante foi criado por Alicia Fernandez [...] e se refere àquele que desperta o desejo de aprender. Seu "par" é o aprendente, aquele em quem esse desejo é despertado. Os dois estabelecem uma relação dinâmica, em que, por vezes, o ensinante se torna aprendente e vice-versa (LUCCHESI, 2005, p.62).

Apesar da necessidade de despertar o desejo de aprender, existe um distanciamento que fica evidente em pesquisa de Teixeira (2011), cujo lócus foi uma escola da rede pública de ensino do Estado de São Paulo. Tendo como objetivos a compreensão de como a criança se percebe diante do ato de conhecer e como a escola, na figura do professor, qualifica este ato. Esse estudo buscou também construir situações de intervenção educativa visando abrir caminhos para novas práticas. A metodologia adotada foi a pesquisa-intervenção de natureza hermenêutica $e$ fenomenológica, em um trabalho prático-teórico. Os resultados levaram à organização de temáticas que, entrelaçadas, possibilitaram a interpretação da situação vivenciada na Escola, revelando que o afastamento de corpos evidenciado não é apenas objetivo, físico, pois é a expressão do distanciamento intersubjetivo, das intencionalidades vivenciadas pelo corps propre (MERLEAU-PONTY, 1999), e que se concretizam ora em rejeição, decepção, alienação, medo, culpa, solilóquio e idealização, ora em realização, busca e diálogo (TEIXEIRA, 2011).

Nesta pesquisa pudemos perceber que tanto professores quanto alunos transitam entre a reprodução e a criação, porém os primeiros estão mais presos aos movimentos reprodutores, talvez porque, ao estarem há algum tempo sujeitos às regras legitimadas 
pela sociedade, têm a tradição mais sedimentada, esquecendo-se da capacidade que tem o homem de criar, improvisar, reinventar e transformar.

Mais ainda, o fato de os professores estarem presos às regras legitimadas pelas tradições empirista e/ou intelectualista faz com que a sua percepção dos outros e a coexistência com eles tornem-se impossíveis, pois tanto o próprio corpo quanto a percepção dos outros corpos tendem a autonomizar-se.

Ficam evidentes as tensões vivenciadas por aqueles que, ao participarem de uma instituição escolar preocupada em transformar, sofrem o embate entre a tradição e o desejo de mudança.

Na trajetória da produção do conhecimento, observou-se que a opção entre mudar e transformar só ocorrerá quando os sujeitos, tendo consciência daquilo que são como humanos, passarem a discernir o que é próprio do homem daquilo que é apenas legitimado socialmente.

Observamos que o aluno se fecha ao que o professor "professa" escudado numa visão idealista racionalista, berço da dita pedagogia tradicional e da educação ocidental considerada culta, e recusa-se a aprender. O professor frustra-se e é cobrado por sucesso ao "ensinar". Mas o que é ensinar se não instigar o aluno a interrogar, a buscar sentidos, a (re)significar, produzir conhecimento? Se o professor não é capaz de aprender ao ensinar, o aluno também não aprende; ambos apenas se desincumbem de uma tarefa angustiante da melhor maneira (im)possível.

Entretanto, como a necessidade de saber é inata no ser humano, ele buscará em outras fontes as informações, construindo as respostas que se fizerem necessárias para a construção do conhecimento de que necessita. A "sociedade em rede" (CASTELLS, 1999) intensificou essa possibilidade, ao disponibilizar uma grande quantidade de informação. Ao mesmo tempo, tornou-se mais exigente quanto à capacidade de produzir conhecimento. Hoje, já não basta conhecer o seu meio local; é preciso, simultaneamente, conhecer o sujeito que aprende e como ele aprende, situado no mundo, num meio que é global, e articular ambos de maneira produtiva, na cultura da "glocalização".

$\mathrm{Na}$ modernidade a escola básica universalizada pretendia adestrar (con-formar) a massa desordenada que migrava do campo para as cidades, de modo a incorporá-la ao processo produtivo, gerando uma mão de obra eficaz para seu correspondente econômico, o capitalismo industrial. A compreensão e a experiência perceptual vivenciada em nossas escolas atualmente, neste contexto da chamada pós-modernidade, imbricada na mundialização do conhecimento, transversalizada pelo capitalismo informacional, ou seja, a "sociedade em rede" (CASTELLS, 1999) e capitais voláteis, demonstra que esta se estagnou no contexto anterior orientado pelo capitalismo industrial e na visão modelada na modernidade, sendo incapaz de solucionar a dicotomia de formação do ser humano para a cidadania ou para o mercado de trabalho. A essência de uma escolarização assim (mal administrada) levou-a a um tipo de niilismo ${ }^{9}$ ao não corresponder nem às expectativas do sujeito que aprende, nem às do indivíduo que deveria adquirir "competências" para o mercado de trabalho capitalista. Mesmo porque só é possível aprender pondo em prática o que se aprende, operacionalizando. A teoria, desvinculada de sua aplicação, não faz sentido.

\section{FORMAÇÃo HUMANA E EDUCAÇÃO: RETOMANDO O TEMA}

\footnotetext{
${ }^{8}$ O Niilismo é a desvalorização e a morte do sentido, a ausência de finalidade e de resposta ao "porquê". Os valores tradicionais se depreciam e os "princípios e critérios absolutos dissolvem-se" (PECORARO, 2007).
} 
$\mathrm{Na}$ formação do professor seria preciso que a teoria estivesse iluminando a prática, de modo que se fizesse uma reflexão desta à luz da primeira, para enriquecê-la e, retornando à prática, transformá-la. Nessa via de duas mãos "[...] a teoria apoia a prática e a prática confirma ou modifica a teoria” (LUCCHESI, 2004, p. 11).

É nesse sentido que defendemos a prática da pesquisa como a base do ensino, a partir das vivências que considerem o conhecimento que se dá no pré-reflexivo de cada sujeito esteja ele onde estiver, cuidando do ensino superior no qual se formam os professores que educarão as crianças e jovens, considerando o ser humano no seu vir a ser. Entendemos que pesquisar não é apenas buscar ou inovar, mas também dialogar com a realidade, questionando-a, de modo a buscar sentidos, gerar interrogações e novas teorias, propor soluções, verificar a aplicabilidade dessas soluções, discutir e encaminhar problemas. Ver-se inquieto, interrogar, pois é no ato da pesquisa que se adota uma postura crítica frente à realidade.

Neste trabalho nos propomos ainda a resgatar o sentido original dos termos formação humana e educação, na perspectiva hermenêutica fenomenológica que tem norteado nossas investigações. Para tanto, ao dizer do tema formação humana e educação primeiramente recorremos a Edith Stein (1891-1942), filósofa e pedagoga, uma das principais assistentes de Husserl, pois essa autora, conforme nos traz Garcia (1988, p. 59), faz uma distinção preciosa ao clarificar os significados atribuídos a esses termos. Recorrendo à terminologia alemã original, quando formação (Bildung) passa a referir-se à totalidade do ser humano, a significar o resultado, a totalidade de um processo educacional. Formação refere-se à própria condição existencial humana, enquanto educação (Erziehung) passa, nessa possibilidade, a ser um termo subordinado, um processo dirigido ao formar, que por sua vez é um processo cultural sempre inacabado.

Considerando o termo educação na sua dupla acepção latina, como $e$-ducare, este nos diz de um processo que se refere à intervenção, à especificação do educativo (MARTINS, 1992).

Mas é ao dizer a educação como um cuidado humano que temos na acepção latina (e-ducere) uma aproximação ao sentido mais forte do termo formação. Educação, na fenomenologia hermenêutica existencial, nos remete à condição humana e às suas possibilidades de apropriação de si mesmo, sendo um processo em que o homem está sempre sendo, condição esta que oscila entre um estado de fascinação pelo mundo (alienação) e uma busca pela apropriação de si mesmo como um ser-com-o-outro no mundo: um ser plural, sempre em perene busca pela autonomia. Um ser em forma-ação.

Educação para o ser em forma-ação deve ter como sublime missão reconhecer o homem na sua humanidade, oferecendo-lhe condições de (con)vivência em sociedade: um homem inscrito no mundo e com o mundo e com os outros homens. Esta é a missão de educar, pois ao reconhecer a si próprio o "educador" reconhece o "outro", dialogando com ele e construindo uma relação ensino/aprendizagem. Educação permeada de valores que perpassam a era que se denomina pós-modernidade e que supõe nova visão de homem/mundo, de homem no mundo e com o mundo, visão esta que deve transformar a sociedade impregnando-a dos "novos valores" que, como nos diz Bauman (1999, p. 289), são "a liberdade, a diversidade e a tolerância".

Retomando o termo formação, um dos conceitos mais caros às ciências do espírito do século XVIII, recorremos ao pensamento de Gadamer (1988), que nos traz o sentido desta palavra como dada no alemão: Bildung.

Esclarecendo-se que compreendemos este termo também como signo, signo este que, ao ser traduzido do alemão para o espanhol como formação traz uma conotação especial, conforme destaca os tradutores: 
Bildung, que traducimos como "formación", significa también la cultura que posee el individuo como resultado de su formación en los contenidos de la tradición de su entorno. Bildung es, pues tanto el proceso por el que se adquiere cultura, como esta cultura misma en cuanto patrimonio personal del hombre culto. Bildung, está estrechamente vinculado a las ideas de enseñanza, aprendizaje y competencia personal ( $\mathrm{N}$. del T.) (GADAMER, 1988, p. 38).

Emerge desta exposição a opção por nós utilizada para dizer de formação (Bildung): formação como sendo o resultado de um processo de vir a ser, algo que nasce de um processo interno de constituição que permanece em evolução e aperfeiçoamento contínuos. Essa compreensão do termo formação é o que torna passível de desconfiança colocar-se como "meta de formação" uma ação de natureza externa ao processo em si, pois esta será sempre secundária a ela. Por outro lado, reafirma que, na formação, tudo é preservado, nada desaparece. Não se trata de adquirir algo qualitativamente novo, ou do que se ensina sobre isto ou aquilo, mas de buscar um saber-se (a si mesmo), vivenciado ou dirigido a algo que não ela (formação) mesma.

\section{EM SÍNTESE}

Retomando a questão proposta, evidenciamos que o conhecimento na perspectiva por nós investigada é tema a ser continuamente interrogado, pois é construído na existência, por aquele que conhece: o homem acontecendo na ação - quando agindo, interagindo, participando, habitando o mundo, torna-se consciente de sua natureza e do que o rodeia como fatos que lhe são próprios e interligados à mesma existência. Os autores verificaram que acontecem avanços substanciais em direção a uma formação humanizadora quando os sujeitos constatam que ocorrem trocas significativas em direção a uma formação humanizadora, quando os sujeitos envolvidos no processo se mostram conscientes daquilo que são como seres humanos individuais e plurais, mais ainda, planetários. Como seres lançados no mundo, um mundo que os precede e alcança e projeta, neste processo de sua humanização encontram facticidades - situações não escolhidas -, limitações favorecedoras para que a heteronomia supere ou dificulte a conquista da autonomia. Entretanto, este modo de ser e estar dialeticamente ao mundo, buscando sempre sentidos, também desvela outras possibilidades humanas, quando como sujeitos, estes seres se encontram existencialmente lançados num círculo hermenêutico. Situados num contexto de mundo em transformação, ao vivenciar uma dialética fina entre as novas compreensões que emergem e os conhecimentos já dados e validados, os homens se educam e são educados, e neste movimento sempre inacabado, produzem cultura... formam -se.

\section{REFERÊNCIAS}

BAUMAN, Z. Modernidade e ambivalência. Rio de Janeiro: Jorge Zahar Editor, 1999.

BLOOM, B. S. Taxionomia de objetivos educacionais. Porto Alegre: Editora Globo, 1977.

CASTELLS, M. Fim de milênio. A era da informação: economia, sociedade e cultura, v. 3. São Paulo: Paz e Terra, 1999.

ESPÓSITO, V. H. C.; SILVA, G. T. R. (Orgs.). Pedagogia social: formação na ação. São Paulo: Martinari, 2012. 
Vitória H. C. Espósito; Martha A. S. Lucchesi; Gilberto T. R. da Silva; Maristela R. de C. Gasonato

ESPÓSITO, V. H. C.; SILVA, M. G. B.; SILVA, G. T. R.; SALOMÉ, G. M. Desenvolvimento humano e a produção do conhecimento: trajetórias de investigação de natureza fenomenológica e hermenêutica. Memorandum, Belo Horizonte, v. 26, p. 153-167, 2014.

ESPÓSiTO, V. H. C.; LATTARI, M. C.; GOLDGRUB, R. G.; PlACCO, V. M. N. S. A primazia da percepção como fundamento do ato criador e o fazer pedagógico. In: MARTINS, M. A. V.; ESPÓSITO, V. H. C. Pedagogo Artesão. Construindo a trama no cotidiano da escola. 3. reimp. São Paulo: Educ, 1999. p. $63-102$

ESPÓSITO, V. H. C. Construindo o conhecimento da criança/adulto. Uma perspectiva interdisciplinar? São Paulo: Martinari, 2006.

ESPÓSITO, V. H. C.; GASONATO, M. R. C. Um diálogo pensante com a poesia: buscando construir práticas de conhecimento. Revista Pesquisa Qualitativa, São Paulo, v. 4, n. 4, p. 51-61, abr. 2016.

GADAMER, H. G. Verdade y método. Fundamentos de una hermenêutica filosófica. 3. ed. Traducido por de Ana Aparício y Rafael de Agapito. Salamanca: Sígueme, 1988.

GARCIA, J. T. Edith Stein e a formação da pessoa humana. Bauru: Edições Loyola e Universidade do Sagrado Coração, 1988.

GASONATO, M. R. C. A pesquisa na ação educativa e a produção do conhecimento. In: ENCONTRO NACIONAL DE DIDÁTICA E PRÁTICAS DE ENSINO, 14., 2008, Porto Alegre. Anais... Porto Alegre, 2008. p. 1-10.

LUCCHESI, M, A. S.; MALANGA, E. B. A superação dos limites disciplinares na universidade brasileira e a pesquisa ambiental. In: TALLER INTERNACIONAL UNIVERSIDAD, MEDIO AMBIENTE, ENERGIA Y DESARROLO SUSTENTABLE, 4., 2008, Havana. Anais... Havana, 2008. p. $1539-1549$.

LUCCHESI, M. A. S. (Org.). Cadernos de pesquisa em pós-graduação. Santos: Leopoldianum, 2004.

LUCCHESI, M. A. S. educar para a cidadania: a psicopedagogia como mediadora do processo ensino/aprendizagem. Cadernos de Psicopedagogia, v. 8, p. 54-67, 2005.

MAFFESOLI, M. O conhecimento comum: introdução à sociologia compreensiva. Porto Alegre: Editora Sulina, 2010.

MARTINS, J. Um enfoque fenomenológico do currículo: educação como poíesis. São Paulo: Cortez, 1992.

MATTELART, A. Sociedade do conhecimento e controle da informação e da comunicação. In: ENCONTRO LATINO DE ECONOMIA POLÍTICA DA INFORMAÇÃO, COMUNICAÇÃO E CULTURA, 5., 2005, Salvador. Anais... Salvador, 2005. p. 1-22. Disponível em: < http://www.gepicc.ufba.br/enlepicc/ArmandMattelartPortugues.pdf >. Acesso em: 07 ago. 2017.

MERLEAU-PONTY, M. Fenomenologia da percepção. São Paulo: Martins Fontes, 1999.

MERQUIOR, J. G. Michel Foucault ou o niilismo de cátedra. Rio de Janeiro: Nova Fronteira, 1985.

PECORARO, R. Niilismo. Rio de Janeiro: Jorge Zahar Editor, 2007.

RICOEUR, P. Du texte à l'action. Essais de hermeneutique II. Paris: Éditions du Seuil, 1996.

NUNES, E. F. P. A.; SAKAI, M. H.; LIMA, J. V. C.; CARVALHO, B. G.; GUTTIERREZ, P. R.; NERY, S.; OLIVEIRA, M. S. M.; BADUY, R. S.; SILVA, A. M. R.; PETRIS, A.; COSTA, E. M. O. D. Construindo espaços para a reflexão e o trabalho multiprofissional. Olho mágico, Londrina, v. 5, n. 18, p. 22-23, mar. 1998. 
SILVA, G. T. R.; ESPÓSITO, V. H. C.; MACIEL, A. F.; SANTOS, I. G.; ZANINI, C. A.; LANDIM, S. A.; BATISTA, N. A. Um estudo de caso: a vivência multiprofissional a integralidade como ações educativas na formação do profissional em saúde. In: OHARA, E. C. C.; SAITO, R. X. S. (Orgs.). Saúde da família: considerações teóricas e aplicabilidade. São Paulo: Martinari, 2010. p. 407-420.

SILVA, Gilberto Tadeu Reis. Preceptoria como ação educativa: uma leitura hermenêutica fenomenológica. 2003. 224 p. Tese (Doutorado em Ciências) - Escola Paulista de Medicina, Universidade Federal de São Paulo, São Paulo, 2003.

TEIXEIRA, M. U. B. Buscando sentidos para o ato de conhecer: perspectivas de estudantes e professores. In: SILVA, G. T. R.; ESPÓSITO, V. H. C. (Orgs.). Educação e saúde: cenários de pesquisa e intervenção. São Paulo: Martinari, 2011. p. 203-218.

TOURIÑÁN LÓPEZ, J. M. Interculturalismo, globalidad y localidad: estratégias de encuentro para la educación. Bordón, Revista de Pedagogía, v. 56, n. 1, p. 25-47, 2004.

UFSCAR. Ecomotricidade e Bem Viver são temas de colóquio internacional na área de Motricidade Humana. Entrevista com o Prof. Dr. Luiz Gonçalves Junior. 07 jul. 2017. Disponível em: < http://www.saci.ufscar.br/servico release?id=97069\&pro=3 >. Acesso em: 07 ago. 2017.

UNIFESP. Projeto Político Pedagógico. Santos: UNIFESP, 2006. Disponível em: < http://prograd.unifesp.br/santos/download/2006/projetopedagógico.pdf >. Acesso em: 26 out. 2007.

Recebido em: 16 out. 2017.

Aprovado em: 29 out. 2017. 